\title{
ACLIMATANDO HUMANOS Y PLANTAS LA PROPAGACIÓN DE COLONOS ECOLOGISTAS EN MISIONES (ARGENTINA)
}

\author{
Gabriela Schiavoni ${ }^{1}$
}

${ }^{1}$ CONICET-Programa de Posgrado en Antropología Social, Universidad Nacional de Misiones, Argentina

\section{Introducción}

Los inmigrantes de origen suizo, cuya propensión a la agroecología aspiro a establecer, forman parte de una colonización efectuada de manera particular, por fuera de los marcos institucionalizados del Estado. Es un poblamiento sin centros, que se extiende multiplicando las conexiones horizontales a través de grupos de hermanos y cuñados, vinculados entre sí mediante re-encadenamientos de alianzas. La continuidad y reproducción de estos individuos se llevará a cabo por inmersión en el ambiente, en interacción con las demás especies.

El acceso a la tierra es el motivo de la emigración. Y, si bien otras zonas de Argentina hubieran resultado más afines al origen suizo, el entonces territorio nacional de Misiones ofrecía tierras baratas junto al interés por poblarlas.

La condición de frontera abierta — desde fines del siglo XIX hasta mediados del XX-, alimentó el carácter multiforme del poblamiento misionero, asemejándolo a la situación de Estados Unidos, donde "el Oeste con sus indios sin ascendencia, su límite siempre escurridizo, sus fronteras móviles y desplazadas, es rizomático" (Deleuze y Guattari, 2004: 24).

La conexión de estos extranjeros con un ambiente que desafiaba las clasificaciones conocidas, se edificó sin la mediación de una infraestructura de saberes agronómicos oficiales, suscitando al mismo tiempo un vínculo de experimentación y asociación inter-especie y un esfuerzo por contener la diversidad, delimitando un cosmos. 
El hecho que muchos de estos inmigrantes quedaran marginados de la agricultura de escala-la plantación de yerba mate, cuyo cultivo fuera prohibido en 1935, en ocasión de la primera crisis de sobreproducción- los impulsó a explorar combinaciones alternativas.

Los encuentros coloniales, advierte Tsing (2019), “nos muestran al Hombre como una erupción. La producción simultánea de universalidad del Hombre y las historias provincianas y vernáculas que lo ligan al lugar son extremadamente visibles en ese espacio, en el que la inconmensurabilidad es la práctica cotidiana" (Tsing, 2019: 211).

El nuevo ambiente estimuló la experimentación y, al mismo tiempo, el despliegue de formas para contener la diversidad. Mi artículo tiene como objetivo describir las acciones de estabilización efectuadas por estos colonos, llevadas a acabo a partir de dos lógicas concurrentes: la lógica aditiva del coleccionista y la lógica sustractiva del seleccionador.

En la senda abierta por los trabajos de Haudricourt (1962) acerca de la relación entre la generación humana y la reproducción vegetal, la originalidad de mi aporte radica en conectar las acciones de vinculación de los inmigrantes — sus estrategias matrimoniales—, con los lazos inter-especie anudados con el ambiente: limitar la diversidad para circunscribir familias y especies, y al mismo tiempo hacerla proliferar, a través de la propagación rizomática de plantas y humanos, con el fin de prolongar la fertilidad y el asentamiento en la tierra.

El material empírico que analicé reconstruye el ejercicio de ambos tipos de prácticas, puestas en marcha por un conjunto de inmigrantes suizos, considerados actores de referencia en la agroecología regional. ${ }^{1}$

Las trayectorias que analizo se diferencian de la oleada de inmigración suiza que llegó a la región una vez concluida la primera guerra mundial, en la que se destaca el grupo de ingenieros agrónomos formados en el Politécnico de Zúrich — uno de cuyos profesores impulsaba el cultivo de yerba mate-, y que arribaron a Misiones con capital, dando origen en 1919 a la colonización privada de Santo Pipó (depto. San Ignacio), a orillas del río Paraná.

Los casos que considero reciben de la esfera pública un apoyo tenue, no disponen de capital y sus devenires obedecen a desplazamientos auto gestionados en base a recursos limitados. Dos de ellos arriban a la región con una preparación específica: Bertoni (1857-1929) es botánico, y Roth (1901-1985), ha realizado estudios de horticultura. Estos son los casos mejor documentados, ya que, además de las biografías eruditas, ${ }^{2}$ contamos con los textos redactados por los propios inmigrantes: manuales de agricultura, consejos ambientales, cartas y memorias. Se trata de escritos que nos proporcionan una aproximación adecuada a la acción, ya que son textos 
que articulan gestos; "tienen por función propia anularse como discurso y producir, en la práctica, conductas y comportamientos considerados legítimos" (Chartier, 1995: 10, 11).

El tercer caso es una familia que se instala en Misiones en 1937, en el marco de un tratado sobre inmigración, firmado por el gobierno argentino y la confederación suiza. Sobre este grupo contamos con el diario escrito por el padre (desde 1937 a 1958), parte del cual fue publicado en Argentina (Gallero, 2008) y el resto en Alemania (Schegg-Loher, 2006), y del que contamos con una traducción inédita. Con respecto a esta familia, disponemos también de datos provenientes del trabajo etnográfico, realizado con los descendientes, en la provincia de Misiones, durante los últimos cuatro años. En este grupo, la propensión a la ecología ocurrirá en la primera generación instalada en América (los hijos del inmigrante suizo).

\section{Multiplicaciones}

En Biology Unmoored. Melanesian reflections on life and biotechnology, Bamford (2007) subraya el interés en conectar los estudios de parentesco con los estudios sobre el ambiente, dada la mutua imbricación de estos campos en el marco biológico.

El modelo folk occidental utiliza la reproducción fisiológica como el criterio para definir la membrecía a una especie, tanto en el caso de los humanos como de los vegetales. Las formas biológicas que pueden cruzarse y producir una prole viable son vistas como pertenecientes a una misma especie. Sin embargo, entre los Kamea, estudiados por Bamford, el potencial reproductivo humano está ligado a otras especies y no se define en contraposición a ellas. Así, la filiación se establece mediante el involucramiento en el lugar, a través de los lazos con las plantas y el paisaje. La condición filial se deriva de la capacidad de seguir las huellas dejadas por el padre sobre la tierra, siendo la linealidad un fruto de esta actividad. Esto hace que los ex-asalariados que retornan con dinero, pero sin el conocimiento de rastros sobre el ambiente, deambulen en busca de tierra, asimilados a los parientes matrilaterales lejanos. Así, la línea que expresa la reprodución de los humanos emerge de la interacción entre especies.

La perspectiva multiespecie (Van Dooren, Kirksey y Münster, 2016; Tsing, 2015; Süssekind, 2018) invita a abandonar la concepción de los organismos como entidades monádicas y ahistóricas, considerándolos aglomerados que se multiplican con y a través de otras especies. 
El enfoque privilegia las conexiones horizontales, las simbiosis y agenciamientos, las mezclas e hibridaciones, a expensas de la filiación o transmisión vertical de tipos puros.

La cruza entre especies, principal elemento de alarma acerca de los OGM (organismos genéticamente modificados) — de acuerdo a una encuesta que analiza Bamford (2007), realizada en Gran Bretaña_, pone de manifiesto el hecho que la comprensión occidental del mundo orgánico descansa en series de tipos naturales definidos en base a su historia reproductiva única. Apoyándose en las reflexiones del biólogo Mayr, la autora localiza este sistema de ideas en el siglo XVII, cuando el botánico John Ray sugirió que la reproducción sexual podía usarse como criterio para clasificar a los organismos en el mundo natural. La ingeniería genética, al tomar genes de un organismo e introducirlo en el cuerpo viviente de otro, resulta inquietante porque compromete la pureza del tipo natural, mientras que la genética tradicional de plantas es más aceptada, ya que no implica traspasar esos límites.

La noción de raza, estructurada en torno a la reproducción sexual dirigida, es retomada por Hartigan (2017), en conexión con la de cuidado. La delimitación de los tipos naturales vegetales sería una derivación de las relaciones entre especies, ya que habría ocurrido vía la protección y observación de los humanos. Los contornos de las razas y sus áreas matrimoniales serían modelados por necesidades y lugares, a través de un régimen histórico de encuentros cotidianos con los humanos.

Las plantas intervienen en este proceso y la comprensión de sus acciones resulta posible mediante la adopción de un pensamiento viviente, alternativo al pensamiento objetivo. Fruto de la observación sensorial y de la apertura hacia el ambiente, este formato nos permitirá emprender un trabajo de campo multiespecie, capaz de detectar las asociaciones y el desciframiento de los lugares contenido en el comportamiento vegetal (Hartigan, 2017: 269).

Una atención de este tipo pone de manifiesto que la diferenciación de los existentes emerge de las formas de contacto inter-especie. En este sentido, la casa, sugiere Tsing (2015), tendría el efecto de aislar el amor intra-especie del amor inter-especie. En las plantations coloniales "con sus mezclas no estabilizadas entre lo que es nativo o extranjero (...) lo silvestre y lo domesticado (...) las cosas podían fácilmente confundirse (Tsing, 2015:191). Allí, las mujeres desempeñaron un rol clave en el mantenimiento de las fronteras, tanto de la casa como de las especies.

En efecto: "Manteniendo sus casas libres de humedad, de mosquitos y de mestizaje, las mujeres blancas en los trópicos se volvieron modelos de alineación de especies y sub-especies (Tsing, 2015:191). 
En el caso que analizo, la continuidad de los humanos dependerá de un doble movimiento: por un lado, las mezclas y lazos entre diferentes, y por el otro, la delimitación de fronteras, en la que las mujeres jugarán un papel relevante. El relato que sigue, documenta este proceso.

Mi razonamiento no está organizado en torno a un paralelismo entre humanos y vegetales, sino que apunta a detectar principios de acción presentes en ambos dominios.

\section{Propagaciones}

A fines del siglo XIX, el interés del Estado argentino en promover la colonización se conjugó con las dificultades económicas en regiones de Europa, entre ellas Suiza. Esto generó movimientos de población hacia la Argentina, considerada la "América de América".

Aconsejado por el geógrafo francés Reclus, Moisés Bertoni, emprende en 1884 el viaje hacia la Argentina, acompañado por un grupo de cuñados, primos y amigos de la misma generación, con el fin de fundar una colonia agrícola en Misiones. ${ }^{3}$

Si bien al principio contó con el apoyo del presidente argentino Julio Roca y su hermano Rudecindo, gobernador del territorio nacional de Misiones, este vínculo institucional no le garantizó el acceso a la tierra. En efecto, aspiraba obtener tierras en la zona de Santa Ana (próxima a la antigua reducción jesuítica, en la fracción sur del territorio), pero cuando solicita la concesión de 16 leguas cuadradas en el valle del río Yabebirí, en 1887, las disputas desatadas con otros interesados lo empujan a trasladarse a Paraguay en 1888.

Allí se instalará primero en Yaguarazapá (100 kilómetros al norte de Villa Encarnación, depto. Itapúa, Paraguay), y luego en Monday, en las proximidades de las cataratas de Iguazú, en tierras del Estado concesionadas con fines de poblamiento agrícola, en las que funda la colonia Puerto Bertoni. $\mathrm{Al}$ aceptar, en 1895, la proposición del presidente del Paraguay de fundar y dirigir la Escuela Nacional de Agricultura, solicita al gobierno que le venda estas tierras, eximiéndolo de la obligación de instalar colonos.

Desplazándose por cuenta propia, Roth arriba en 1926 a la colonia de Santo Pipó (depto. San Ignacio, Misiones), fundada por la oleada inmigratoria posterior a la primera guerra mundial con apoyo de capital privado suizo. Allí encuentra que los lotes "están todos reservados". Accederá a la tierra en este lugar, adquiriéndola a un comerciante, propietario de dos parcelas remanentes que habían sido entregadas al agrimensor como pago por sus 
servicios. Según relata: “Cien hectáreas costaban diez mil pesos [\$100/ha] (...) Justo una suma que podía reunir de mi herencia, para adquirir al menos la tierra" (Roth en Gallero, 2014: 95).

Roth había tenido noticias de Misiones a partir de la lectura del libro del Dr. Schuster, ${ }^{4}$ que difundía la experiencia de Bertoni. Según cuenta: "Nada sabía de Misiones en aquel entonces. Pero ahora recuerdo que en Basilea había comprado un antiguo libro de un médico suizo (...) Contaba mucho sobre la colonia Bertoni (...) Allí vivía un botánico e investigador suizo que estaba a cargo de la estación meteorológica y poseía cultivos de bananas, café, caña de azúcar, yerba mate, algodón y quizás cien especies más. Observaba el clima, la naturaleza, el suelo, el bosque. El Dr. Schuster decía que todo lo que vio y observó en Puerto Bertoni, valía también para el territorio de Misiones" (Roth en Gallero, 2014: 84). ${ }^{5}$

En el mismo año que Roth se instala en Misiones, llega de Suiza un cuñado suyo- el hermano menor de su esposa—con la idea de "tener aquí su propio campo, con una o más vacas. Vino sin dinero y descubrió unos terrenos detrás de Santo Pipó (La Pequeña) cuya dueña vendía parcelas de 25 ha pagaderas a plazos. Financió la compra de tierra, con su sueldo de vendedor en una empresa suiza de la localidad (Bugnion-Fitting - Lecoultre, hoy Santo Pipó SA)" (Roth en Gallero, 2014: 158). Los dos cuñados se asociarán luego en la producción de yerba mate, constituyendo la sociedad Roth y Würgler S.R.L.

A su vez, en las tierras fiscales de los valles serranos del centro-sur de Misiones, se irán instalando otros suizos "en forma particular". A través de un formato de este tipo, llegan los hermanos Lutz. El menor de ellos se encontraba trabajando en el establecimiento de un pariente en la provincia de Buenos Aires, cuando en 1917 recibe la visita de uno de sus hermanos mayores, que había decidido emigrar hacia Misiones. Este, una vez establecido en las tierras fiscales (Ensanche Cerro Corá) de la zona de O. V. Andrade (depto. L. N. Alem, Misiones), se dedicó al cultivo de tabaco y llamó a su hermano menor, que arribó a la localidad en 1919. Ya en Misiones:" [los hermanos Lutz] tienen noticias de Yerbal Viejo (actual Oberá, en el centro de Misiones) donde les informan que hay tierras inexplotadas que pueden apropiarse para plantar yerba mate. Ocupan los lotes 70 y 71 de la tercera sección de la colonia Picada de Bonpland a Yerbal Viejo, ubicados alrededor de lo que es hoy un acceso a la ciudad de Oberá" (Gualdoni Vigo, 2007: 49). Solicitan luego dichos lotes a la Dirección de Tierras, en el momento en que llega a la Argentina un tercer hermano, con su mujer e hijo, y se instalan en las recién obtenidas parcelas de Yerbal Viejo. 
Finalmente, una tercera oleada de poblamiento suizo ocurrirá en la década de1930, cuando estalla la crisis económica y aumenta el desempleo en Europa. Con el fin de descomprimir la situación, el gobierno suizo subsidió la emigración ultramarina y firmó un tratado sobre inmigración y colonización con el gobierno argentino en 1937, configurándose la provincia de Misiones como un destino posible. Dado que el precio de la tierra era menor que en la zona pampeana, el consulado hace un contrato con la Compañía Colonizadora Eldorado, que disponía de grandes extensiones de tierra para colonizar en el Alto Paraná misionero. ${ }^{6}$ Aún así, los inmigrantes subvencionados que consideramos aquí, accederán a la tierra por fuera de este marco institucional, instalándose "en forma particular" sobre extensiones fiscales.

El comisionado suizo recorre el territorio de Misiones en 1937 (Ferrari, 1942) desalienta esta vía de acceso a las parcelas. En su visita a la zona central, próxima a Oberá, advierte: “Desgraciadamente existe una dificultad (...) Estas tierras son de propiedad fiscal. Su adquisición es teóricamente fácil y prácticamente muy posible. Pero, cuánto tiempo hace falta para obtener los títulos de propiedad a favor del respectivo colono?" (Ferrari, 1942: 150).

La compra-venta de mejoras, formato característico de acceso a la tierra por parte de los pequeños agricultores, y dispositivo básico de expansión de la frontera agraria de Misiones (Schiavoni y Gallero, 2017), no ofrece garantías para el comisionado. En efecto: "si un colono adquiere de segunda mano, es decir, del ocupante actual, un lote ya labrado, pero aún no definitivamente otorgado en propiedad, lo que le adquiere y le paga su sucesor son únicamente las mejoras existentes (...) la Dirección Nacional de Tierras tiene el derecho de no aprobar semejantes traspasos, de anular la adjudicación del respectivo lote al desaparecer el primer ocupante, y hasta de incautarse de las mejoras existentes en el mismo" (Ferrari, 1942:150).

Uno de los casos que preocupa especialmente al funcionario es el de la familia Schegg, que integra nuestra selección de casos. Afirma: "Yo quisiera visitar sobre su propia chacra al colono Jakob Schegg, quien ha llegado de Suiza, hace 4 meses escasos, con su esposa y 12 hijos (...) Schegg, un humilde labrador escribe de una forma que sorprende (...) me decía que 'él y los suyos daban gracias al Señor y a las Autoridades suizas que le habían permitido establecerse en su nueva morada', en la que 'había de comer para todos'" (Ferrari,1942:146-147).

El interés del comisionado tiene que ver con el origen fiscal de la tierra sobre la que se ha asentado el suizo subvencionado. Refiere: 
Jacobo Schegg se ha establecido (...) en esas condiciones y ello ha originado mi alarma, y mi intervención antes el sr. director de la oficina Nacional de Tierras en Posadas, quien tuvo a bien darme la seguridad de que no habría de objetar esta operación de traspaso y hubiera, al contrario, autorizado este último a favor del mismo Schegg, otorgándoles un certificado provisional por el lote de tierra que ocupaba" (Ferrari, 1942: 150-151)

Jacobo Schegg se asentó sobre las tierras fiscales porque el precio era menor. Relata su decisión de emigrar, en estos términos: "Crisis, tiempos malos, falta de trabajo (...)También a través de Suiza (...) Tengo 12 chicos (...) Un día un amigo me comenta, que en América del Sur (...) las cosas son mejor y que la Confederación paga un subsidio a emigrantes desocupados" (en Gallero, 2008: 71). En 1935 su solicitud es aceptada y en 1937 emprenden viaje. Cuando llega a la Argentina, el destino previsto es la localidad de Ruiz de Montoya, como las demás familias suizas, pero recibe la oferta de una chacra más barata en la zona de Oberá, en colonia Samambaya. ${ }^{7}$ Se trata de una explotación "ya empezada" (en producción), que tiene ganado, yerba - cuyo cultivo estaba prohibido-, casa y galpón. El precio por 25 ha era de \$6000 (\$240 por ha., incluyendo las mejoras, en Gallero, 2008:75). Aún así, era mucho dinero y sólo después de varias negociaciones, adquirió la chacra por $\$ 3200$ (\$128 por ha, incluyendo las mejoras). ${ }^{8}$

Las impresiones del comisionado sobre los subvencionados instalados en el marco del contrato entre el gobierno suizo y la Compañía colonizadora del Sr. Schwelm en el Alto Paraná misionero (el "Valle de los suizos" en el kilómetro 28 de la colonia El dorado), dan cuenta de las dificultades de las familias para solventar los compromisos de pago de las parcelas adquiridas a la empresa.

En la visita a dicha colonia, el funcionario enlaza otra extensión de la ramificación suiza, ya que se encuentra trabajando allí "el agrónomo Ing. Bertoni, hijo del sabio Dr. Moisés Bertoni, mi ilustre compatriota que ha fallecido hace unos años y sobrevive en obras que, como 'Prehistoria y Protohistoria de los Guaraníes' y la 'Civilización Guaraní' honran su nombre en este rincón del mundo" (Ferrari, 1942: 111).9

\section{Aclimataciones}

En su tratado sobre la domesticación, Saint Hilaire (1861) define esta noción, diferenciándola de los grados menores de injerencia humana: la aclimatación y la naturalización. Así, la aclimatación consiste sólo en la "adecuación de un individuo o de una raza a un conjunto nuevo de 
circunstancias" (Saint Hilaire,1861:143), mientras que la naturalización supone la conversión de especies extranjeras en nativas, situando el origen del término en la lengua del derecho. ${ }^{10}$ Finalmente, la domesticación "que es la conquista más completa" (Saint Hilaire,1861:155), implica el control de la reproducción y el establecimiento "de una serie de individuos, surgidos unos de otros, una raza" (Saint Hilaire,1861:155).

Estos diferenciales de interacción entre especies tienen consecuencias en la delimitación de las fronteras entre los organismos. Así, Bertoni subraya las ventajas del mestizaje en la aclimatación de los colonos extranjeros. ${ }^{11}$ Este reconocimiento, sin embargo, se mantiene en fricción con la tendencia delimitadora de conformación de un enclave suizo. En efecto, hacia a fines del siglo XIX, cuando obtiene del gobierno paraguayo la concesión de 12 leguas cuadradas para colonizar, le escribe a su hermano, que permanece en Europa, en los siguientes términos:

Están reunidas todas las condiciones para formar aquí una verdadera y fuerte colonia extranjera. Pero a este respecto nunca he podido vencer la resistencia que opone mi familia (...) aún sigo en la situación de rechazar a los colonos que se ofrecen (...) el poblado se va formando poco a poco por la fuerza de las cosas (...) Sólo que en lugar de estar poblado por suizos, alemanes, etc. lo está por criollos e indios (...) Estaré entonces obligado de continuar sobre el mismo pie: colonia de familia con el agregado de una población obrera criolla (Bertoni en Baratti y Candolfi, 1999: 80-81).

\section{Y continúa:}

Casi todos mis hijos prefieren tratar con los 'hijos del país' antes que con los extranjeros. Es cierto que (...) [el europeo] muestra una ignorancia crasa en todo aquello que no se vincula a su único trabajo, mientras que nuestro criollo es ingenioso (...) es el rasgo guaraní lo que domina en el cruzamiento, toma la delantera como una raza superior. El hijo de un europeo y de una indígena está del lado de la madre (Bertoni en Baratti y Candolfi, 1994: 433)

Garantizar la continuidad intergeneracional constituirá una preocupación de estos inmigrantes, tanto en relación a los humanos como con respecto a las variedades vegetales y al mantenimiento de la fertilidad del nuevo ambiente. En lo referente a las plantas cultivadas, privilegiarán las uniones próximas, al interior de una misma especie. En efecto: "Los productos de la hibridación de dos especies son esencialmente inestables; en las generaciones sucesivas varían continuamente" (Bertoni, 1927: 45), mientras que los productos de los cruzamientos entre variedades de una 
misma especie, "no presentan ese inconveniente sino en un grado mucho menor, de manera que es posible remediarlo mediante la selección (...) [que] permite fijar la forma o tipo que más convenga" (Bertoni, 1927: 45).

Controlando las mezclas, la consecuencia que se busca neutralizar es la multiplicidad, multiformidad e inestabilidad de las asociaciones inter-especies.

En este sentido, también la "guachería"12 es condenada, ya que tiene como consecuencia la pérdida de control de la reproducción sexual y, por ende, la inestabilidad transgeneracional. Refiriéndose a una variedad de algodón, afirma Bertoni:

El algodonero criollo del Paraguay es muy bueno pero la Gran Guerra (186570) causó su abastardamiento y es difícil encontrar tipo puro. Después de la catástrofe nacional el cultivo fue casi abandonado, la selección se volvió negativa. El algodón más temprano y hermoso se recogía para el pequeño uso doméstico y los capullos peores y más tardíos quedaban para la reproducción natural o 'guachería' (Bertoni, 1927: 64).

Asimismo, alerta acerca de los riesgos que entraña la multiplicación de mandioca a partir de semillas, ya que la semilla recogida de una misma planta, produce a veces plantas venenosas y plantas dulces a la vez. La reproducción por esquejes, en cambio, ordena la indiferenciación y permite controlar la descendencia.

De igual manera, sus observaciones sobre las variedades de maíz de la región están orientadas a prevenir los cruzamientos no intencionales entre diferentes. Afirma: "Lo que ahora pasa en el Paraguay y Misiones es una vergüenza, pues a tal punto se van dejando entrecruzar todas las variedades (...) que es frecuente recibir partidas de maíz que no se sabría en qué grupo clasificar" (Bertoni, 1927: 122).

Y, agrega: "Seguramente la hibridación oportuna y científicamente hecha puede dar muy buenos resultados; pero ¿̇quién la hace? En cambio, es sabido ahora que el entrecruzamiento desordenado de numerosos tipos mal definidos, no lleva sino a una confusión de tipos continuamente variables" (Bertoni, 1927: 124).

Los tipos vegetales se consolidan como variedades y especies bajo el cuidado de los humanos. Se trata, sin embargo, de resoluciones provisorias, ya que retienen su potencial de transformación.

En este sentido, la yerba mate, un género silvestre cuyo cultivo fuera iniciado por los jesuitas en el siglo XVIII, ejemplifica la tensión entre la propagación, representada por la aclimatación de plantas huérfanas o guachas, y la domesticación a través de la reproducción por semillas, requerida por la gran plantación. 
Dado que la técnica de germinación había desaparecido junto con el abandono de las misiones jesuíticas en el siglo XVIII, los empresarios interesados en el cultivo a gran escala, llevaron a cabo numerosos ensayos a fines del siglo XIX para obtener la reproducción a partir de semillas. ${ }^{13}$

El formato mono-especie impuesto por el control humano tuvo como consecuencia la pérdida de diversidad. Bertoni alerta al respecto:

Comercialmente, se llama 'yerba mate' o 'te del Paraguay' al producto de la especie Ilex paraguariensis exclusivamente (...) El porvenir se encargará de demostrar, probablemente, que tan estricta definición no es tampoco conveniente. Estoy convencido de que esta especie clásica no es la sola aceptable, y tengo serios indicios de que no sea la mejor (Bertoni, 1927: 475)

En fricción con el encuadre comercial que incentiva la intimidad con unos pocos cultivares, Bertoni y los agricultores suizos que seguirán su rumbo, operarán de manera aditiva, fomentando la interacción entre las diversas especies vegetales y con las prácticas y conocimientos locales, desvalorizados por la lógica de la plantation.

\section{Naturalizaciones}

La estabilización de los agrupamientos de humanos resultaba tan crucial como la delimitación de las especies vegetales en la empresa agrícola y científica emprendida por Bertoni. La magnitud transgeneracional de la obra lo impulsó a planificar los matrimonios de sus hijos, con el fin de reclutar colaboradores, poniendo en tensión el control paterno y las conexiones espontáneas derivadas del arraigo en el nuevo ambiente. La disponibilidad de tierras operó como un incentivo para atraer yernos e importar esposas de Suiza.

El apogeo de la Estación Agronómica de Puerto Bertoni tiene lugar hacia 1910, "cuando retiene todavía el conjunto de sus hijos y los matrimonios de sus hijas le deparan colaboradores, como (...) Schrottky [entomólogo alemán], y el estudiante Juan Gimenez (...) Se constituyó un buen conjunto de trabajo, entre los hijos Arnoldo, Guillermo Tell (1889-1963), Moisés Santiago (18871967) y sus dos mencionados cuñados" (Contreras Roque, 2019:19).

La organización y distribución de tareas era la siguiente: "el Ing. Juan Bautista Gimenez, esposo de la hija Vera tenía a cargo el laboratorio químico y de experimentación agrícola. Curt Schrottki, zoólogo, entomólogo, esposo de la hija Inés, era un gran colaborador (...) Winkelried, uno de sus hijos mayores, estuvo a cargo el Museo de Ciencias Naturales de Puerto Bertoni 
los diez años que su padre permaneció como director de la Escuela Nacional de Agricultura en Asunción. Los hijos del medio, Guillermo Tell y Moisés Santiago, también tenían funciones asignadas. El primero se ocupaba de los experimentos agrícolas de aclimatación de vegetales exóticos, del canje y selección de semillas y administraba la Revista Agropecuaria de la Sociedad Nacional de Agricultura, fundada por el padre. En 1928 se aleja para asumir un puesto de inspector técnico" (Bertoni \& Bertoni, 1984: 29,30). Por su parte, su hijo Moisés Santiago era Ingeniero Agrónomo y colaboró en la impresión de la obra escrita por su padre. En 1926 dejó Puerto Bertoni porque Adolfo Schwelm le propuso la asesoría agrícola de la Compañía Eldorado de Colonización en Misiones.

En una carta escrita a su hermano en 1912, Bertoni afirma: "Necesito casar a mis hijos. Fui muy feliz con mis yernos, pero lo sería menos con mis futuras nueras, no me preguntes por qué" (Baratti y Candolfi, 1994: 469)

A semejanza de lo manifestado a propósito de los vegetales, el objetivo buscado son las alianzas estables. ${ }^{14}$

En 1910, con el fin de conseguir esposas para sus hijos Bertoni se pone en contacto con la joven hija de una prima suya, acariciando el sueño de un matrimonio en familia. Dirigiéndose a ella, afirma: "la única que continúa la línea de los Bertoni en el modesto pero noble nido de nuestra familia" (Baratti y Candolfi, 1994: 402). Y en intercambio epistolar que entablan, declara: "veo en tu semblante el representante puro de nuestra raza, una verdadera Bertona, con todas nuestras virtudes de familia" (Baratti y Candolfi, 1994: 449).

También anuda un compromiso para casar al segundo hijo varón con una prima de Suiza, en este caso, la hija de una hermana de su esposa. Este arreglo se rompe y en una carta enviada al hermano en 1913, Bertoni lamenta la situación, afirmando: "De mis hijos, él era el que la naturaleza y las circunstancias parecían haber designado como el mejor sucesor de nuestra lignée, el más indicado para transmitir a la posteridad, con nuestra sangre, una herencia intelectual. Pensé que permanecería vinculado a mi obra, primero como colaborador y luego como primer continuador y sucesor. Ahora bien, una vez roto el compromiso, y dado que hay dos hermanos siguientes que ambicionan ese lugar, ella podría viajar (desde Suiza), sin que nadie la presione y elegir libremente" (Baratti y Candolfi, 1994: 459).

En la carta enviada a esta muchacha, describe a sus dos otros hijos casaderos, en los siguientes términos: "tengo que decirte que Tell y Moisés sólo esperan para casarse que se encuentre una mujer de nuestro agrado. Son hombres educados, responsables, muy dedicados a la familia y a sus padres de los que no piensan separarse" (Baratti y Candolfi, 1994: 462). 
Solicita a su hermano que interceda e intente convencer a la sobrina, y también, si fuera posible a sus hermanas y su madre para que se trasladen a Paraguay. Y agrega: "Nuestras dos familias, hechas para unirse, para completarse una a la otra, para ayudarse mutuamente en la lucha por la vida, ligadas por un afecto nunca desmentido, se verían separadas (...) sin más que el triste derecho de amarse en silencio" (Baratti y Candolfi, 1994: 469).

Sobre los cónyuges varones, comenta: "Estoy muy satisfecho con mis yernos, sin excepción (...) Schrottky Curt es miembro del comité central de la asociación internacional de entomólogos (...) y los tres paraguayos se encargaron de hacerme aún más simpática esta raza criolla nacional, tan mal conocida y tan meritoria" (Baratti y Candolfi, 1994: 464). ${ }^{15}$

El ideal del matrimonio con mujeres de la familia y del país de origen está orientado a consolidar un tipo puro, estable: el tronco suizo o alineamiento vertical que continuará su obra. A partir de las modificaciones de este tronco, fruto de la naturalización en el nuevo ambiente, la familia se extenderá como un rizoma, en sentido horizontal, mediante re-encadenamientos de alianzas con los parientes políticos criollos. Así, el hijo del medio Guillermo Tell se casa con la hermana de la mujer del hermano mayor (Reto). Y Moisés Santiago, uno de los prometidos de la prima de Suiza, se casará con la prima hermana de Santiago Flores, el esposo de su hermana Aurora. En la generación siguiente, el hijo de Inés Bertoni y Curt Schorottki se casará con la hija de Vera Zasulic Bertoni, que había desposado a Juan Bautista Gimenez.

El entrecruzamiento transversal de múltiples hilos tornará difusa la línea sucesoria, poniendo en riesgo la estabilidad transgeneracional, tan apreciada por Bertoni a propósito de los tipos vegetales y humanos. Así, en 1929, unos meses antes de su muerte, el sabio le escribe a un colega, relatándole que se encuentra "sin sucesores ni colaboradores, sin hijos ni nietos", mencionando el conflicto con el yerno Gimenez, que le acusa de no haber cumplido con la palabra de otorgarle la propiedad la tierra. ${ }^{16}$

\section{Domesticaciones}

La imposición de una única historia reproductiva con el fin de delimitar fronteras entre variedades y especies - el in breeding suizo que Bertoni no alcanzó a aplicar en su prole - constituirá un rasgo característico de la reproducción de los inmigrantes suizos que arriban a Misiones en los inicios del siglo $\mathrm{xx}$.

Los matrimonios se anudarán entre suizos y el viaje a la madre patria en procura de cónyuges mujeres será una constante de esta población. 
En 1917, un joven suizo residente en O. V. Andrade (Misiones), se casa por poder (a distancia) con una joven compatriota que conoce a través de un aviso periodístico. El matrimonio de su hermano menor, en 1929, con una nativa brasilera de la localidad de Bompland, se convertirá en fuente de discordia familiar. ${ }^{17} \mathrm{El}$ carácter étnicamente segregado que caracterizaba los ámbitos matrimoniales en la provincia de Misiones, a comienzos del siglo XX, se evidencia en el testimonio de una colona sueca que envía una carta a sus parientes en el año 1924, relatando: "el hijo mayor me ha provocado mucha pena, se ha comprometido con una mestiza sueca-brasilera y no suficiente con eso también piensa ser bautista" (Schiavoni y Urquiza, 2000: 124).

En otro caso, el hijo de un inmigrante suizo relata la trayectoria migratoria y matrimonial del padre en los siguientes términos:

Mi papá (...) vino en el año 1928 (...) a O. V. Andrade. En un encuentro (...) con varios colonos (...) le comentaron que se formaba una colonia suiza en Oro Verde donde plantaban yerba. Eso lo entusiasmó y decidió ir allí. Al principio trabajó con Federico Heuer, hasta que pudo comprar 25 ha de tierra. Allí hizo su ranchito de pindó y sus plantaciones propias. Sin embargo le faltaba una compañera y decidió ir a Suiza con la ilusión de encontrarla (...) Después de varios encuentros y charlas (...) se casaron en la iglesia evangélica de Amsoldingen en 1932. Al poco tiempo viajaron a Misiones (en Gallero, 2008: 142)

También el cuñado de Roth, que arribó a Misiones en 1926, emprenderá un viaje a Suiza para casarse. Acerca de esta situación, Roth recuerda:

Creo que fue en 1933 cuando Pablo Würgler pensó en casarse. Candidatas no le faltaban, las había entre chicas de 15 años y mujeres de 50, todas criollas. ${ }^{18}$ Pero sabiamente Pablo se mantuvo lejos de ellas. En cambio viajó a Europa para buscar, mediante un aviso, una novia, una mujer. (...) A último momento Ruedi [su hermano] y Juliette Würgler le presentaron a la señorita Greti Schmutz" (en Gallero, 2014:178, 179)

En "Suizos en busca de una esposa" (en Gallero 2008), el hijo ofrece un relato de dicha-experiencia:

En 1926 [mi padre] vino a Misiones con la firme intención de trabajar diez años, ganar dinero y volver a Suiza (...). Pasados los diez años (...) había adquirido chacras, plantado yerba mate con buena cosecha y en realidad se sentía muy a gusto en Misiones, pero le faltaba la esposa para formar familia. (...) Junto a dos amigos solteros (...) viajó a Suiza en el año 1934 (...) Durante el viaje (...) se ponen de acuerdo que en Suiza se presentarán mutuamente sus hermanas, primas. (...) Uno de sus hermanos (...) vivía en Milán y (...) decide visitarlo 
(...) Margarita [futura esposa] era amiga de la esposa de Rodolfo [hermano]" (Gallero, 2008: 127,128)

El comisionado del gobierno suizo que recorre Misiones en 1937, se sorprende ante la importancia de la inmigración por cuenta propia de jóvenes suizos que reclaman cónyuges de la madre patria:

Ignoraba que hubiese (...) tantos suizos solteros, que se han establecido aquí en los últimos años, con sus propios medios. Todos los que me abordan se declaran satisfechos con los resultados obtenidos, y casi todos me confían que quisieran traer a la novia, que han dejado en Suiza con la idea de llamarla una vez ya instalados (Ferrari, 1942: 53)

A su vez, Roth, cuando queda viudo en 1951, vuelve a casarse al año siguiente con la hermana de su esposa, residente en Suiza, que había estado casada previamente con un hermano suyo. Como relata la editora de sus memorias:

Dos mujeres de esta familia fueron las compañeras de vida de Alberto, Gritli en primera instancia, con la cual tuvo sus dos hijas (...); y una vez viudo, se casó en segundas nupcias con Clemi, un poco menor, quien a su vez había estado casada con su hermano Carlos. Fue así que Alberto adoptó a sus sobrinos Marthe, Heinrich y Christoph como hijos. Especialmente mantuvo una relación muy cercana con Christoph (Stöffi), quien vino a la Argentina por un tiempo y luego regresó a Suiza para afincarse definitivamente en Inglaterra(Gallero, 2014: 158) ${ }^{19}$

El caso de la familia Schegg que ya mencionamos - un suizo subvencionado que se instala en forma particular sobre las tierras fiscales del centro de Misiones - resulta ilustrativo, ya que cuando los hijos están en edad de casarse (el mayor tiene proyectado retornar a Suiza), arriba a la localidad (en 1947) otra familia suiza, con la que toman contacto a través del consulado. A lo largo de diez años (1949-1959), estas dos familias anudarán cinco uniones, involucrando a hijos e hijas de las fratrías respectivas. Son alianzas que combinan el in breeding suizo, la proximidad local y los matrimonios entre parientes políticos que multiplican las conexiones transversales. En su diario, el padre relata:

En el año 1947 comenzó otra etapa en nuestra existencia de colonos. Los varones mayores empezaban a sentir los aires de primavera (...) Se debían 'meter' mis muchachos con argentinas? Estas se clasifican, en lo que respecta a Misiones, mi patria electiva, en tres clases: $1^{a}$ clase: hijas de los que están más arriba 
(...). Luego la $2^{\mathrm{a}}$ clase: los quedados mestizos, inclinados a la holgazanería y de escasos recursos. A esta se agrega $\left[3^{\circ}\right]$ un sinnúmero de descendientes de sectarios (...) que solo aceptan a aquellos que ingresan a su comunidad de portadores de la verdad bíblica (...) Justo en este tiempo de añoranza primaveral, vino a caer la inmigración de la familia de Otto Weber de Wülflingen, con 9 hijos, 4 chicas y 5 varones (...) Rápidamente se anudaron lazos de amistad. La amistad se convirtió en amor y comunión (Schegg, 2006, traducción inédita)

Y, continúa el relato del padre:

Como las hormigas podadoras inician todos los años su vuelo nupcial y fundan nuevas colonias, así ocurría ahora con la juventud suiza, pero al parecer las mujeres argentinas tampoco están muy cotizadas entre nuestros varones. O tal vez interviene algo de la añoranza suiza en el enamoramiento! Como resultaron las parejas quiero señalar con algunos nombres: Daniel Schegg se casó con Ruth Weber; Reinhard Schegg con Heidi Weber; Alfons Schegg con la Esther Weber; Hans Kluser se casó con Blanka Schegg; Benedikt Schegg con Ida Freiberger y Karl Weber con la Monika Schegg (Schegg, 2006, traducción inédita)

Uno de los efectos de los enlaces así concertados fue la estabilidad. Como señala una de las mujeres involucradas en estas uniones: "Todos estos matrimonios fueron buenos y festejaron los 50 años de casados" (entrevista, Oberá, 2018).

Asimismo, las cinco alianzas anudadas entre las dos familias suizas dieron como resultado un colectivo de setenta y cuatro personas, vinculado por lazos de parentesco y autosuficiente en el plano de la sociabilidad cotidiana. Una de las integrantes refiere: "No necesitábamos ir afuera! Siempre era con los primos: para jugar, para tener amigos" (entrevista, Oberá, 2019).

Es decir, en este caso, la práctica del re-encadenamiento de alianzas entre parientes políticos, semejante a lo puesto en marcha por los hijos de Bertoni con cónyuges criollos, tuvo lugar en el marco del in breeding suizo.

Así, multiplicando las conexiones horizontales, estas colonias de familia estabilizaron el agrupamiento sin que la filiación fuera el factor determinante. Como señalé en un trabajo anterior (Schiavoni, 2005), referido a las nuevas colonias de la frontera agraria de Misiones, los re-encadenamientos de alianzas entre parientes políticos delimitan conjuntos a través de la proliferación de lazos transversales, obviando la estructuración vertical, fundada en la genealogía. El contorno emerge como un efecto del espesamiento de la trama generado por la duplicación de matrimonios. 
También en el poblamiento planificado de la primera mitad del siglo XX - en las colonias públicas y privadas de Misiones - encontré referencias a prácticas matrimoniales de este tipo, tendientes a establecer entrecruzamientos. Los intercambios de cónyuges (varones y mujeres) entre fratrías constituyeron una figura recurrente en la colonia de Puerto Rico (depto. San Martín, Misiones; Salvador, 2004), así como la duplicación de alianzas a través del casamiento entre consuegros, incluida en un relato sobre la colonia de Apóstoles, al sur de Misiones. ${ }^{20}$

Al multiplicar las conexiones laterales, casándose entre sí, las familias "hacen colonia", ya no por la vía institucional del poblamiento planificado, ni por referencia a un ancestro fundador. Delimitan contornos consolidando agrupamientos acentrados, que vibran sobre sí mismos, en un sentido análogo al del término meseta utilizado por Bateson - región continua de intensidades que se desarrolla evitando cualquier orientación hacia un punto culminante -, y que, como recuerdan Deleuze y Guattari (2004: 32), es la misma palabra que se emplea en francés (plateau) para describir el engrosamiento del tallo en bulbos, tubérculos y rizomas.

La coherencia de estos colectivos no se deriva de una línea genealógica, sino de la propagación de ramificaciones laterales. A semejanza de la metáfora botánica de Doutté, citada por Berque a propósito de las poblaciones nómades de África del norte: "no son ramas crecidas de un mismo tronco, sino yemas, continuos injertos realizados sobre un pie primitivo que se vuelve a veces imposible de discernir" (Berque, 1974:24). Situados entre la casa y las instituciones, varios de estos colectivos familiares están en el origen de las asociaciones cooperativas de Misiones.

\section{Desafiliaciones y alianza con la selva}

Deleuze propone la 'cartografía' como un análisis alternativo a la arqueología. No se trata de buscar un origen ni de atenerse a determinaciones genealógicas, sino de evaluar desplazamientos. Desde esta perspectiva: "Lo que el analista mapea, son milieus [medios, ambientes] y trayectorias, senderos que la gente toma a través de los milieus para perseguir sus necesidades, deseos, y curiosidades" (Bielh y Locke, 2010: 323). Trayectorias y milieus existen en presencia mutua; se mantienen en fusión, en contra de la causalidad de los orígenes y el peso de la memoria.

El desplazamiento de los inmigrantes aquí analizados en el milieu selvático - muchos de ellos obreros fabriles, algunos con educación técnica - estimuló la experimentación con la naturaleza y el vínculo inter-especie. La selva transformó a los humanos tanto como éstos a ella. 
En este sentido, la agricultura de la región, condenada por los representantes oficiales enviados a Misiones a principios del siglo XX, en virtud del lazo estrecho que mantiene con la selva y con ciertas prácticas indígenas, tales como el empleo del palo cavador (Yssouribehere, 1904), será apreciada desde esta perspectiva no familiar, reconociéndola como un tipo específico: la agricultura silvícola. ${ }^{21}$

La preferencia por el cultivo en áreas de monte, así como la preparación mínima del suelo serán consideradas prácticas apropiadas, en ruptura con la tradición europea de agricultura cerealera.

Al poco tiempo de llegar al territorio de Misiones, luego que fracasara su proyecto de aclimatación de especies exóticas - 900 tipos de plantas, provistas por la sociedad de aclimatación de Francia (Ortiz, 2004:141) - Bertoni escribe lo siguiente: "roturar la tierra es envenenarla; por cuanto con esa operación ella pierde su humedad, y después las plantitas que nacen, encuentran una superficie encendida, no pueden más resistir a la violentísima insolación tropical" (Bertoni, 1984: 65).

$\mathrm{Al}$ enumerar las contribuciones más originales de su tratado sobre agricultura subtropical (publicado en 1903, 1926 y 192722), menciona el nuevo método de plantación de banano, una aplicación de agricultura selvícola o montaraz. ${ }^{23}$

De la hibridación con las poblaciones locales — especialmente los grupos guaraníes con los que interactúa Bertoni-, emergerá un saber original, en el que los humanos no constituyen el único agente transformador. La práctica de consorciar especies, propia de los rozados indígenas, que delega en la interacción vegetal el mantenimiento de la fertilidad, estará en la base de sus principios de agronomía subtropical.

Esta concepción será operacionalizada en la recomendación de intercalar leguminosas, retomando las variedades de la región y restituyéndoles su origen indígena, en ciertos casos.

Así, sobre el Phaseolus lunatus, conocido como poroto soperí y muy cultivado en Paraguay y Brasil, señala: "su verdadero nombre guaraní Ihsoperi; los indios cultivan variedades de gran crecimiento y granos más gruesos y de diferentes colores" (Bertoni, 1927: 225).

El carácter inventivo que adquiere la alianza con los saberes y prácticas locales se manifiesta también en la catalogación que efectúa de la yerba dulce o kaá he ’é, de cuya existencia le advierten los indios y vaqueanos locales. Empleada como edulcorante por los guaraníes, recibirá de Bertoni la denominación de Stevia Rebaudiana, en homenaje al químico Rebaudi, a quien le encarga el estudio de la composición química de esta planta (Bertoni, 1984: 21).

Las plantas medicinales del país constituirán un tema de fuerte interacción entre los inmigrantes y la población nativa. Bertoni combate la opinión negativa de los extranjeros al respecto y relata lo siguiente: 
De los colonos suizos que yo traje a Misiones en 1884, el más instruido dejó morir a su hijo después de largo sufrimiento, de una invasión de piques (niguas) por haber ido a vivir en un rancho abandonado, sin previa desinfección. Muchos brasileros y paraguayos que en el lugar vivían (Santa Ana) indicaban al padre y a la madre (esta era partera, educada en Ginebra) cuan sencillo era, con plantas del país, librarse de eso y desinfectar el rancho. Nada creyeron (Bertoni, 1927b: 172)

La cohabitación inter-especie, fundamento de la agricultura selvícola, significa quebrar "el vínculo privilegiado que Occidente mantiene con el bosque y con el desmonte; los campos conquistados al bosque se plantan de gramíneas, objeto de una agricultura de familias, basada en la especie y de tipo arborescente"(Deleuze y Guattari, 2004: 23).

Sin embargo, como advertimos al inicio, el recorrido que efectúa Bertoni está guiado por dos fuerzas que se mantienen en fricción: por un lado, el interés en la asociación humano- vegetal, y, por el otro, la voluntad de creación de un orden, un cosmos instituido por los humanos. Así, en su tratado de agricultura subtropical sistematizará el tiempo, estableciendo la "división del año en temporadas", con el fin de organizar el trabajo agrícola en la región (Bertoni, 1927:6).

Roth sigue las huellas que deja Bertoni mediante la lectura de los escritos del naturalista y a través de los relatos de la hija de éste. Refiere lo siguiente:

Tengo en mi memoria muchos detalles (...) que me había narrado la tercer hija del doctor Bertoni: 'Tía Wera' (....) las primeras impresiones (...) que él mismo anotó con fecha del 9 de julio de 1884 (...) 'Los europeos no me creerán: este suelo no requiere arado. Se voltean los árboles, se los quema y se siembra directamente (...) Innecesario es preparar la tierra, innecesario abonarla, pues contiene la fuerza necesaria en exceso'(Roth, 2017: 34)

$\mathrm{Al}$ conectar la actividad humana con la de las especies selváticas, estos prácticos-letrados experimentaron con la variación, dando nacimiento a una nueva agricultura, sintetizada en la fórmula que más tarde enunciará Roth: "la chacra es la continuación inteligente del monte", y cuyas derivaciones concretas serán el rozado sin quemar y la cubierta verde.

Estos desplazamientos suscitaron controversias técnicas con respecto a las prácticas establecidas, que operaban a contrapelo de la asociación entre humanos y vegetales, tal como la costumbre del deshierbe o escardado que busca eliminar los intentos colonizadores de las hierbas silvestres. Bertoni calificará el deshierbe como "una rutina tránsfuga de la agricultura europea" (1927: 445). Roth, por su parte, relata: 
Mientras que en 1938 y en los años siguientes se hacía todo lo posible para mantener el suelo limpio, sacando yuyos (...) yo traté de hacer algo distinto, diferenciando las malezas, dejando las que crecen en invierno y tienen raíces largas y delgadas que mantienen la humedad del suelo (Gallero, 2014: 273)

Mirar minuciosamente el trabajo de sus peones le servirá a Roth "como un manual" de tratamiento del suelo subtropical (Gallero, 2014: 261). En efecto:

El paraguayo avanzaba a toda velocidad (...) Con su azada bien afilada, de 30 a 40 centímetros de ancho y mango largo, pasaba por encima de los yuyos, cuyos tallos generalmente seguían asomándose del suelo (...) Muy diferente el brasileño! Con una azada más angosta comenzó a sacar los yuyos de raíz" (en Gallero, 2014: 260)

\section{Y continúa:}

Como campesino novato me di cuenta de que había [que] observar cómo iban a reaccionar las plantas y el suelo a esos dos métodos de trabajo tan diferentes (...) iel buen y diligente trabajo del brasileño no era el indicado! iEl trabajo superficial, aparentemente malo del paraguayo era el método correcto! (en Gallero, 2014: 261)

El arraigo en la tierra constituirá la marca de éxito de los colonos, y al mismo tiempo la fuente de sus dificultades. Roth padece este límite y por eso considerará la naturaleza esencialmente en términos de suelo, planteando una alianza con las hierbas silvestres para el mantenimiento de la materia orgánica.

Orientada a contrarrestar el problema de la pérdida de la fertilidad, la técnica de la cubierta verde con Vicia Villosa, una leguminosa que aporta nitrógeno al suelo, constituirá una práctica inaugurada por Roth y su cuñado y socio. El descubrimiento de esta planta es presentado en sus memorias como un hecho fortuito. La editora relata:

Comenzaron a sembrar avena, un cereal que crece muy bien en invierno, da alimento para animales y deja en primavera un buen manto que cubre el suelo. La semilla la compraban por bolsas que venían del sur (Buenos Aires, Santa Fe, Entre Ríos). Junto con la semilla de avena llegó a Santo Pipó semilla de Vicia Villosa [Zottelwicke] mezclada, y no sólo germinó bien sino llamó la atención por el gran volumen de materia orgánica que producía y que cubría el suelo (...) Su buen resultado hizo que (...) sembraran con el tiempo en todos los yerbales y para la venta (Gallero, 2014: 254) ${ }^{24}$ 
Asimismo, Roth y su cuñado experimentan con el subproducto del procesamiento del tung (Aleuritis fordii), un nuevo cultivo introducido en Misiones en la década de 1940.

El expeller de tung ${ }^{25}$ se convertirá en el abono ideal para revertir la disminución de la productividad de los yerbales, reutilizando las inservibles cáscaras desechadas por la cooperativa Santo Pipó Tung Oil.

Sus prácticas de manejo del suelo recibirán consagración en el año 1957, en ocasión de la visita de un especialista mundial en el tema, Hugh Bennet, de origen norteamericano. Las innovaciones más apreciadas serán precisamente aquellas que incluyen la asociación entre especies, tales como la cubierta vegetal del suelo de las plantaciones y la idea de plantar yerba en un claro del bosque. Esta alianza de los humanos con la selva fue saludada por el especialista norteamericano en los siguientes términos: "En los Estados Unidos hemos pecado muchas veces, hemos destruido los bosques y ahora tenemos tan pocos árboles, que éstos son tratados como santos" (en Gallero, 2014: 286).

El vínculo de asociación con la naturaleza de los colonos-letrados se transmitirá al conjunto de sus connacionales a través de la Comisión Social Suiza, creada en 1946. Mediante cartas circulares se difunden consejos acerca de la experiencia agrícola en Misiones, y Roth participa en la redacción, tratando temas técnicos tales como: combate de langostas, preparación del suelo, método indore de fabricación de humus, ${ }^{26}$ la tragedia de la tierra quemada, cómo se planta yerba mate. ${ }^{27}$

Estos agenciamientos con el monte, sumados al hecho de la relativa ausencia del Estado, favorecieron el trastocamiento del orden genealógico. Ya no es el padre quien detenta el monopolio del saber porque la cadena transgeneracional ha sido hibridada por la experimentación de los agricultores letrados.

Recordemos que en muchos casos, especialmente los suizos subvencionados que arriban a fines de la década de 1930, se trata de una población sin antecedentes agrícolas. ${ }^{28}$

En uno de estos hogares, por ejemplo, el desconocimiento paterno del ordeñe de vacas hace que el hijo asuma la tarea cuando arriban a Misiones. De acuerdo al relato del progenitor: "Para el ordeñe ha sido designado Daniel, de catorce años. El lo aprendió en la Patria con el amigo Augusto, mientras que yo no ordeñé nunca una vaca" (en Gallero, 2008: 81).

Este hijo - el mayor de la familia Schegg -, califica como desventura la experiencia de los suizos que migran a Misiones, en un relato que remite en 1947 a Roth, para ser publicado en las cartas circulares de la Comisión Social Suiza. 
Los suelos frágiles de los valles serranos del centro de Misiones ("tierras magras"), en las que se asentó el grupo, limitaron sus posibilidades de "hacer la América". Esta familia experimentará con cultivos alternativos, tales como el ramio (China grass ${ }^{29}$ ) y el yute (Corchorus capsularis), desarrollando una incipiente industria de fabricación de sogas, a partir de la energía generada por una rueda hidráulica que funcionó desde 1943 a 1946.

En ruptura con el legado paterno, los hijos de este inmigrante establecerán nuevas cartografías, explorando recorridos alternativos. De este modo, a los 56 años de edad, el hijo mayor, se trasladará a las extensiones inexplotadas de la frontera agraria provincial, participando del último plan de colonización pública de Misiones (el Plan Andresito, llevado a cabo en 1978, Pyke, 1998).

Este desplazamiento será al mismo tiempo un distanciamiento con respecto a la tradición mono-especie de las prácticas agrícolas establecidas. Según cuenta:

Yo no soy ecologista porque estoy en Andresito. Antes tuve una chacra chica, pero siempre me preocupé por la contaminación, por la erosión, por los problemas que surgen del manejo tradicional que tenemos en Misiones. Aquí se dice que una chacra linda es aquella que está planchada como una calle, con la tierra roja expuesta a la erosión y a la insolación. Para mí fue una gran satisfacción poder empezar de nuevo en Andresito y evitar algunos errores que hemos cometido antes (...) demostrar que el hombre puede progresar sin necesidad de destruir o alejarse de la naturaleza (Diario El Territorio, Misiones, 27/6/93) ${ }^{30}$

Haciendo una travesía más corta, la hija menor de esta familia establecerá un mapa propio, reconvirtiendo a la agroecología una pequeña granja de 3 ha, en las proximidades de la ciudad de Oberá en 1998.

\section{Consideraciones finales}

Conectar el dominio del parentesco con la esfera de los vínculos con el ambiente me permitió describir los agenciamientos llevados a cabo por un puñado de inmigrantes suizos en las tierras libres, o frontera agraria de la provincia de Misiones y del sudeste de Paraguay. Bajo el formato de "colonia particular", estos agricultores esbozaron sus propios mapas, expandiéndose al margen del poblamiento planificado.

A diferencia de la colonización, que filia al Estado la acción de habitar, los procesos aquí descriptos propagan el poblamiento sin la guía de un genitor. 
Las zonas de compromiso desordenado así engendradas propiciaron el contacto entre diferentes y las asociaciones inter-especies. Los inmigrantes, librados a sus propias fuerzas, anudaron con la naturaleza una alianza inesperada.

La aclimatación involucró a las plantas y también a los humanos. En ambos dominios, las acciones se derivaron de la fricción entre tendencias: el modelo purificador que disciplina y separa, y el desborde de dicho proceso por la proliferación de las mezclas.

Los devenires selváticos de los colonos se alojaron en la asociación entre la agricultura y el monte, intensificando la conexión inter-especie. El modelo occidental de conquista y dominio fue subvertido por la "guachería" y la ramificación silvestre.

La naturalización de los inmigrantes se efectuó oscureciendo los alineamientos genealógicos, a favor de la propagación de los brotes laterales. En vez de consolidar troncos, las familias hicieron bulbo, mediante engrosamientos horizontales, derivados de la multiplicación de las alianzas en el grupo local y con los parientes políticos.

La domesticación, a su vez, exigió disciplinar los apareamientos con el fin de establecer la continuidad de la descendencia, con miras a establecer las fronteras de variedades y grupos puros. El cierre de la alianza en el conjunto de los parientes por alianza y/o en la nacionalidad suiza y la localidad, favoreció el entrecruzamiento y restó nitidez al trazado de la descendencia. A semejanza de lo acontecido con las variedades vegetales, la continuidad estuvo dada por una trama de parecidos de familia antes que por una línea constituida por individuos con rasgos exclusivos.

De este modo, los inmigrantes se tornaron receptivos al ambiente y al mismo tiempo buscaron ordenarlo utilizando los recursos existentes. La resolución de las dificultades mediante la administración de las tensiones del propio dominio dio nacimiento a una eco-lógica que los particularizará.

El conjunto de casos seleccionados me permitió subrayar el carácter no genealógico del lazo entre el origen suizo y la propensión a la ecología, describiendo los meandros de relaciones económicas, políticas y técnicas que fueron ligando históricamente estos atributos. Como un rizoma, los inmigrantes extendieron sus prolongaciones laterales, re-afiliándose a la supra-familia de la agricultura selvática o inter-especie.

Si bien mi artículo describe la experiencia de los agricultores suizos en la provincia de Misiones, las consecuencias del punto de vista multiespecie adoptado son más amplias. En efecto, los vegetales, aunque son participantes indirectos, puesto que conocemos su accionar a través de las prácticas humanas, componen agenciamientos que evidencian una mutualidad entre plantas y humanos. 
Así, la multiplicación rizomática de bananos — sin extraer ni quemar los árboles del monte-, propuesta por Bertoni, manifiesta la alianza de la agricultura con la selva. También la fertilización vegetal, pregonada por estos suizos esclarecidos, resulta reveladora de la afinidad entre los humanos y las plantas, ya que si bien las cubiertas verdes pueden ser sembradas, su origen legitima el papel de las dinámicas silvestres, no intencionales, en los procesos de domesticación.

Aclimatar, naturalizar y domesticar dejan de verse como acciones humanas sobre una naturaleza inerte para convertirse en un único proceso, un tejido sin costura, fruto de la interacción inter-especie. El dépaysement favorece esta experiencia del ambiente como un conjunto de existentes con los que es necesario establecer conexiones. El cambio de milieu desconcierta y revela el carácter interespecie de la naturaleza humana. Así, los espacios de relacionamiento engendrados por el fenómeno del poblamiento agrícola no enteramente controlado por el Estado o las empresas, actualizan un vínculo inventivo con el ambiente.

La perspectiva generada promueve una lectura inhabitual de las fuentes relativas a la colonización, cuyo tono antropocéntrico es característico, ya que están centradas en la reconstrucción épica de la experiencia de los pioneros en su lucha contra la selva. Enfocadas desde el punto de vista del compañerismo interespecífico, estas mismas fuentes dejan al descubierto un tejido de materiales activos que sustenta el proceder conjunto de los humanos y las plantas.

El carácter relacional de la eco-lógica que describí emerge del hecho que los humanos aquí analizados no sacrificaron la naturaleza a su propia lógica, pero tampoco sacrificaron su propia lógica, creando un conjunto original, que a diferencia de otras experiencias de instalación de colonos en Argentina, evidenció el rol decisivo desempeñado por la propagación espontánea y auto-engendrada. Dicho proceso descansó en la atención simultánea al estímulo de la diversidad - la alianza con el monte-, y a la necesidad de establecer un orden (estabilizar familias de plantas y humanos; técnicas y ritmos agrícolas).

En el análisis que realicé, el ambiente dejó de ser el fondo estático contra el que se desarrollan las acciones civilizatorias de los pioneros, convirtiéndose en un medio dinámico, un ensamblaje constante de vegetales, humanos y demás organismos. 


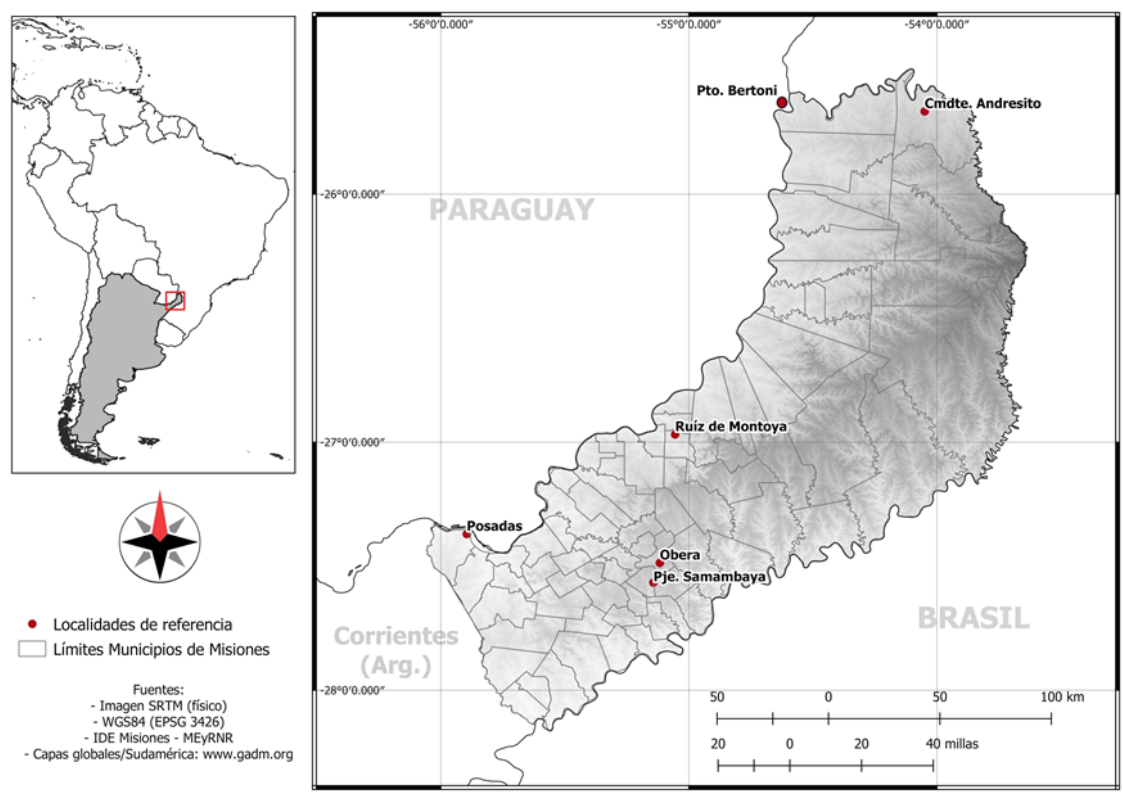

Recibido en 4 de julio de 2020

Aprobado en 6 de enero de 2021

Gabriela Schiavoni

Doctora en Antropología por la Universidad de Buenos Aires, Investigadora del Consejo Nacional de Investigaciones Científicas y Técnicas y docente del Programa de Posgrado en Antropología Social de la Universidad Nacional de Misiones. Es autora y compiladora de numerosos libros y artículos. Sus temas de interés son los estilos de agricultura, el parentesco, la frontera agraria, los procesos de diferenciación social y los vínculos entre los humanos y las plantas. https://orcid.org/0000-0001-5931-2875

E-mail: gabrielaschiavoni4@gmail.com 


\section{Notas}

1 La familia ecologista de Misiones no se compone exclusivamente de inmigrantes suizos. También pertenecen a ella colonos alemanes, ya sea venidos directamente de Alemania, o alemanes-brasileros, tales como Waidelich, Rau y Baumgratz (Schiavoni, 2020).

2 En el caso de Bertoni, contamos con las obras de Baratti y Candolfi (1994 y 1999) que incluyen la publicación de la correspondencia de Bertoni y sitúan la experiencia biográfica en el contexto histórico y geográfico. Con respecto a Roth, disponemos de la edición de sus memorias, realizada por Gallero (2014).

3 En la carta a un amigo, Bertoni describe la composición de la comitiva que lo acompañará a Misiones: "Antonio Magri, mi primo, con su mujer Tellina e hijos; Carlo Bruni, mi cuñado, ya en Argentina; Federico Rossetti, hermano de mi mujer; Hilario Rosetti con su mujer e hijos; Modesto Capriroli con su esposa, que es hermana de la de Hilario, y finalmente Vanina Celso di Giovani" (Baratti y Candolfi, 1994: 212).

4 Se refiere al libro de Adolf Schuster, denominado Argentinien, Land, Volk, Wirtschaftsleben und Kolonisation publicado en 1913.

5 Entre los maestros reconocidos por Roth figuran Bertoni, Pfeiffer (discípulo de Rudolf Steiner) y Albert Howard, fundador de la agricultura orgánica.

6 La compañía vendía la tierra al precio de 110 pesos por hectárea. El convenio de abril de 1937 con el gobierno suizo: 70 pesos por hectárea (Ferrari, 1942 :64).

7 Se trata de una zona de tierras fiscales, con pobladores asentados en forma no planificada ("intrusos"), que en 1936 tuvieron participación activa en una protesta agraria conocida como "la masacre de Oberá" (Waskiewicz, 2002; Castiglioni, 2018).

$8 \mathrm{Al}$ mes siguiente de su arribo a Misiones, el compatriota Leo Lutz le acompaña a Posadas para transcribir a su nombre la tierra. "La escritura en Oberá no alcanza, la Embajada suiza desea encarecidamente que yo vaya. Es por la obtención del título definitivo, por el que más adelante deberé pagar 900 pesos al Estado Argentino" (Gallero, 2008: 84, 85).

9 De acuerdo a este relato, el hijo de Bertoni atiende el jardín botánico del fundador de Eldorado, descripto como "un parque soberbio (...) en una extensión de casi doscientos mil metros cuadrados, a orillas del gran río (...) los más raros ejemplares de la flora de cinco continentes se hallan aquí reunidos" (Ferrari, 1942: 108).

10 "Naturalizar (...) es 'acordar a un extranjero los derechos y privilegios de los que gozan los naturales del país' hacer un natural de un individuo que era un extranjero" (Saint Hilaire,1861: 149). 
11 Afirma: "el aclimatamiento de la raza blanca, en las extensas regiones tropicales de América es posible mediante la mestización (Bertoni, 1922: 158, 159). Y, continúa: "Blancos y Amerindios, mezcla tan favorable, que un octavo de sangre india basta para asegurar un resultado muy satisfactorio, y aún perfecto" (Bertoni, 1922: 160).

12 Guacho: Se usa en Argentina y Uruguay. Dicho de una planta cultivada: Que nace sin ser sembrada. Del quechua Wakcha: Pobre, huérfano, desamparado, sin familia.

13 Uno de ellos relata: "en 1892, Adrián Kury obtuvo 60 plantas que le mandaron del Iguazú. Eran plantas nacidas espontáneamente al pie de los árboles de yerba mate del monte, que los nativos llamaban guachas. (...) Benedetto de San José consiguió criar un lote de 800 plantas obtenidas por acodos hechos de árboles de yerba que había en las Ruinas de San José desde la época de los jesuitas. Estos meritorios ensayos no resolvían del todo el problema de hacer plantaciones en alta escala" (Nuñez, 1997:116).

14 El problema con la familia paraguaya es que renuncia con excesiva facilidad al matrimonio: "Es desgraciadamente la costumbre del país; cerca de la mitad de los matrimonios son irregulares y más de la mitad de los hijos son ilegítimos.(Baratti y Candolfi, 1999:85).

15 Uno de sus yernos le sucederá en el cargo de Director de la Escuela de Agricultura de Paraguay. En una carta, escrita a su hermano en 1907, Bertoni relata: "Mi yerno el Ing. Agrónomo Juan Bautista Gimenez fue nombrado Director de la Escuela [de Agricultura] en lugar mío" (Baratti y Candolfi, 1994: 405).

16 Después de la muerte de Bertoni, su nieto regresará a Pto. Bertoni para continuar las tareas. Se trata de: "Sigisfredo, hijo de Inés y Curt Schrottky. No lleva el apellido Bertoni no tendrá retorno de gloria por su contribución silenciosa ‘a la gran obra'. Fue el curador para la Sociedad Científica del Paraguay de la publicación de un estudio sobre la lengua guaraní, una monografía sobre los guayakí y una sobre las maderas del Alto Paraná, publicadas entre 1940 y 1943 (...) Su mujer, Gertrudis Gimenez (...) es la hija menor de Vera Zasulic Bertoni" (Baratti y Candolfi, 1994:149).

17 Se trataba de una joven oriunda de Brasil, hija de un descendiente de portugueses y cuya madre tenía "algo de descendencia alemana" (Gualdoni Vigo, 2007: 66).Entre los argumentos esgrimidos para fundamentar la oposición "figuraban los raciales , por cuanto decían que (...) no era alemana pura" (Gualdoni Vigo, 2007: 70).

18 La editora aclara que si bien emplea el término eingeboren, que significa indígena, se está refiriendo a hiesig, habitantes del lugar, pero no a guaraníes.

19 El consejo de administración de la Fundación Alberto Roth está definido en términos parentales. Aparece descripto en la edición de su libro Cartas Misioneras(Roth, 2017) en los siguientes términos: "Presidente: Juan Rodolfo Würgler (sobrino de Alberto Roth); Vicepresidente: Bruno Pablo Urfer (sobrino-nieto de Alberto 
Roth); Secretaria: Maria Elena W. De Zimmerli (sobrina de Alberto Roth); Tesorero: Gerald Axel Netter(bisnieto de Alberto Roth)" y, finalmente un extrafamiliar: vocal primero: Alejandro M. Korol (Roth, 2017: 163).

20 El relato describe el matrimonio de un colono con su consuegra, la madre de la esposa del hijo. Está escrito en tercera persona, a partir de la perspectiva de la madre política: "Clementina explicaba que si llegase a darse esa posibilidad [casamiento con una extraña], al fallecimiento del suegro, dicha mujer heredaría el $50 \%$ de la chacra y su hija, nietas y yerno, se verían condicionados a dejar la chacra, dado que el remanente lo tendrían que dividir entre los [tres] hermanos" (Sychowski, 2015: 202, 203).

21 "La agricultura selvícola puede reducirse al desmonte y limpieza del terreno y para ciertos cultivos, sencillamente a la limpieza y raleo del bosque natural" (Bertoni, 1927: 386).

22 En las últimas ediciones bajo el nombre de Agenda \& Mentor agrícola. Guía del agricultor \& colono con el calendario de todos los trabajos rurales.

23 En efecto: "consiste esencialmente en desmontar (défricher) y plantar sin quemar ni extraer nada de los productos de la selva" (Bertoni, 1927: 144). Describe el procedimiento en cuatro pasos: “La primera operación es 'rozar' (...) cortar toda la vegetación baja del bosque, herbácea, arbustiva y trepadora, dejando parado lo que es costumbre cortar con hacha (...) La segunda operación es excavar los hoyos (...) para plantar los bananos. Todos los árboles del bosque están parados todavía. Pero en la práctica esto no impide trazar alineaciones derechas (...) La tercera operación es plantar (...) empleo únicamente los rizomas (...) por la razón de que cada rizoma emite de 2 a 5 brotes, los cuales crecen con fuerza a causa de la reserva alimentar contenida en el rizoma, que es como una gran papa o tubérculo (...) La cuarta operación es voltear o cortar los árboles" (Bertoni, 1927:144-147).

24 Sin embargo, en su tratado de agricultura subtropical, Bertoni ya recomendaba esta leguminosa como estrategia para conservar la fertilidad del suelo. Afirma: "Varias Vezas (vicia) resultaron aclimatables. Pero la que mejor resultó fue la Vicia Villosa" (Bertoni, 1927: 225).

25 Es la harina prensada que se obtiene luego de extraer el aceite del Tung. Dicho desecho aportó nutrientes básicos como el nitrógeno y fue lo que permitió incrementar la producción de forma excepcional.

26 El método Indore de compostaje, basado en la descomposición de una mezcla de desechos vegetales y excrementos animales periódicamente humedecidos, nació de las experiencias realizadas por el inglés Albert Howard desde 1905 hasta 1947.

27 Estas cartas dejaron de publicarse en 1961, cuando se formalizó la preparación técnica de los agricultores suizos a través de la fundación del Instituto de Agricultura en Línea Cuchilla (Ruiz de Montoya, Misiones). 
28 El relato de un representante de la iglesia suiza que acompañó el poblamiento, señala: "los colonos recién llegados no podían plantar más yerba. Probaron con yute, una planta fibrosa (...). La base económica más sólida la posee aquel colono que (...) también ejerce un oficio" (en Gallero, 2008:100, 101).

29 Se trata de "una fibra vegetal de multiplicación rizomática, que se difunde como alternativa a la plantación de yerba mate" (Tschumi, 1948: 211).

30 Y, continúa Schegg: "Andresito tiene una responsabilidad mayor. Si logramos imponer el criterio de muchos que aquí trabajan (orgánicamente), podríamos servir como ejemplo para otras colonias y hasta para el mundo, en cierto porque podría atraer a un turismo que se convencería de que el hombre puede convivir con la naturaleza" (Diario El Territorio, Misiones, 27/6/93) 


\section{Bibliografía}

BAMFORD, Sandra. 2007. Biology Unmoored. Melanesian reflections on life and biotechnology. Berkeley, Los Angeles y Londres: The University of California Press.

BARATTI, Danilo; CANDOLFI, Patrizia.1994. L'arca di Mosè: biografia epistolare di Mosè Bertoni. Bellinzona: Edizioni Casagrande. . 1999. Vida y obra del sabio Bertoni. Asunción: Helvetas.

BERQUE, Jacques. 1974. "Qu'est-ce qu'une tribu nord-africaine?". In: J. Berque, Maghreb, histoire et sociétés. Gembloux-Alger: Duculot. pp. 22-33. BERTONI, Moisés. 1922. La Civilización Guaraní Parte I Etnología. Puerto Bertoni: Imprenta y Edición Ex Sylvis.

. 1927. Agenda y mentor agrícola: guía del agricultor y colono. Puerto Bertoni: Ediciones Ex Sylvis. . 1927b. La Civilización Guaraní Parte III Conocimientos. Puerto Bertoni: Imprent y Edición Ex Sylvis.

BERTONI, Jesús; PECHE de BERTONI, Alida. 1984. Vigía de la selva. Posadas: Copilandia.

BIELH, João; LOCKE, Peter. 2010. "Deleuze and the Anthropology of Becoming". Current Anthropology, vol. 51, nº3: 317-351.

CASTIGLIONI, Guillermo. 2018. Pedimos pan, nos dieron balas. Análisis de un acontecimiento en el marco del proceso de colonización de la región dorsal central, Territorio Nacional de Misiones (1936). Posadas: Editorial Universitaria.

CHARTIER, Roger. 1995. Sociedad y escritura en la edad moderna. La cultura como apropiación. México: Instituto Mora.
CONTRERAS ROQUE, Julio. 2019. Arnaldo de Winkelried Bertoni (18781973). Primer zoólogo paraguayo. Buenos Aires: Fundación Azara de Historia Natural- Universidad Maimónides.

DELEUZE, Gilles; GUATTARI, Félix. 2004. Mil mesetas: capitalismo y esquizofrenia. Valencia: Pretextos.

FERRARI, Luis .1942. En misión a Misiones. Buenos Aires: Librería y Editorial La Facultad.

GALLERO, Cecilia (comp.). 2008. El llamado del oro verde. Buenos Aires: Araucaria.

GALLERO, Cecilia (ed.). 2014. Querida Misiones, hermosa!: a través de las memorias de Alberto Roth. Buenos Aires: Araucaria.

GUALDONI VIGO, Enrique. 2007. El Señor Oberá. Historia de don Basilio Lutz. Buenos Aires: Ediciones El Escriba.

HAUDRICOURT, André. 1962. "Domestication des animaux, culture des plantes et traitement d'autrui". L'Homme, 2, 1: 40-50.

HARTIGAN, John. 2017. Care of the Species: Races of Corn and the Science of Plant Biodiversity. Minneapolis: The University of Minnesota Press.

NUÑEZ, Julio. 1997. Iviraretá.Posadas: Ediciones Instituto Montoya.

ORTIZ, Luis Carlos. 2004. La colonización suiza en Misiones. Posadas: Creativa. PYKE, Jorge. 1998. La expansión de la frontera agraria en el Nordeste de Misiones. El Plan de Colonización Andresito 1978-1983. Posadas: Universidad Nacional de Misiones. ROTH, Alberto. 2017. Cartas Misioneras. Posadas: Gráfica Norte S.R.L. 
SAINT HILAIRE, Geoffroy. 1861. Acclimatation et domestication des animaux utiles. Paris: Librairie Agricole de la Maison Rustique.

SALVADOR, Claudio. 2004. Fundadores en Tierra Colorada. Posadas: Editorial Universitaria.

SCHEGG-LOHER，Jakob. 2006. Als Siedler in Argentinien Misiones. Mels-Bad Ragaz: Sarganserländer Verlag ( traducción inédita).

SCHIAVONI, Gabriela. 2005."'Hacerse parientes' Estrategias de alianza y reproducción social de los ocupantes agrícolas en el NE de Misiones (Arg.)". Anuário Antropológico: 95-118.

. 2020. "Imitar y fabricar. Las naturalezaculturas de las agriculturas guaraní, colona y agroecológica". Horizontes Antropológicos, 26, 56: 165-193.

SCHIAVONI, Gabriela; URQUIZA, Yolanda. 2000. Fuentes Orales, Historia y Antropología. Posadas: Editorial Universitaria.

SCHIAVONI, Gabriela; GALLERO, Cecilia. 2017. "Colonización y ocupación no planificada. La mercantilización de la tierra agrícola en Misiones(1920-2000)". Travesía, 19, 1: 77-106.

SÜSSEKIND Felipe. 2018. "Sobre a vida multiespécie". Revista do Instituto de Estudos Brasileiros, 69:159-178.

SYCHOWSKI, Juan. 2015. Historias de mi familia. Buenos Aires:Araucaria Editora.

TSCHUMI, Eric.1948. Tierra Colorada. Buenos Aires: Talleres Gráficos Alemann y Cía.

TSING, Anna. 2015. "Margens Indomáveis: cogumelos como espécies companheiras". Ilha, 17, 1: 177-201.

TSING, Anna. 2019. Viver nas ruínas. Paisagens multiespécies no Antropoceno. Brasília: IEB Mil Folha. van DOOREN, Thom; KIRKSEY, Eben; MÜNSTER, Ursula. 2016. "Estudos multiespécies: cultivando artes de atentividade". ClimaCom, 3, 7: 39-66.

WASKIEWICZ, Silvia. 2002. La masacre de Oberá, 1936. Posadas: Editorial Universitaria.

YSSOURIBEHERE，Pedro. 1904. Investigación agrícola en el territorio de Misiones. Buenos Aires: Compañía Sud-Americana de Billetes de Banco. 
ACLIMATANDO HUMANOS Y

PLANTAS. LA PROPAGACIÓN

DE COLONOS ECOLOGISTAS EN

MISIONES (ARGENTINA)

Resumen

Desde una perspectiva multiespecie, mi artículo describe las acciones de estabilización de lo diverso llevadas a cabo por inmigrantes suizos en la provincia de Misiones (nordeste de Argentina). A través de una alianza con la naturaleza, dieron nacimiento a una agricultura silvícola, combinando estrategias de purificación y de tolerancia a las mezclas. Desde fines del siglo XIX hasta las primeras décadas del siglo XX, estos agricultores multiplicaron núcleos de poblamiento en las tierras libres de la región, al margen del Estado y del diseño planificado. La estabilización de la diversidad se debatió entre el modelo genealógico y el desborde generado por el entrecruzamiento espontáneo. Los contornos de las variedades de plantas y de humanos emergieron en conexión con el ambiente, sin ser el producto de una imposición externa. La resolución de las dificultades planteadas por la agricultura subtropical administrando las tensiones inter-especies dio nacimiento al proceder ecológico.

Palabras clave: Multiplicación, Filiación, Multiespecie, Domesticación.
ACCLIMATIZATION OF HUMANS

AND PLANTS. THE SPREAD

OF ECOLOGICAL FARM ERS IN

MISIONES (ARGENTINA)

Abstract

From a multi-species perspective, my article describes the acts of stabilizing diversity carried out by Swiss immigrants in the province of Misiones (northeast Argentina). Through an alliance with nature, they gave birth to a silvicultural agriculture, blending strategies of purification with a tolerance for mixing. From the end of the 19th century to the first decades of the 20th century, these farmers multiplied settlement nuclei in the free lands of the region, disregarding the State and planned design. The stabilization of diversity was a struggle between the genealogical model and the overflow generated by spontaneous interbreeding. The contours of plant and human varieties emerged in connection with the environment, and were not product of external imposition. The resolution of the difficulties posed by subtropical agriculture managing interspecies tensions forged the ecological procedure.

Key Words: Multiplication, Filiation, Multispecie, Domestication. 


\author{
ACLIMATAÇÃO DE SERES \\ HUM ANOS E PLANTAS. \\ A DISSEMINAÇÃO DE COLONOS \\ ECOLÓGICOS EM MISIONES \\ (ARGENTINA)
}

\title{
Resumo
}

Partindo de uma abordagem multiespécie, meu artigo descreve as ações de estabilização realizadas pelos imigrantes suíços na província de Misiones (nordeste da Argentina). Através de uma aliança com a natureza, eles deram origem a uma agricultura selvícola, combinando estratégias de purificação e tolerância a misturas. Desde o final do século XIX até as primeiras décadas do século $\mathrm{XX}$, esses agricultores multiplicaram núcleos de assentamentos nas terras livres da região, independentemente do Estado e do planejamento. A estabilização da diversidade foi uma luta entre o modelo genealógico e as misturas espontâneas. Os contornos das variedades vegetais e humanas emergiram em conexão com o meio ambiente, sem serem produto de imposição externa. A resolução das dificuldades colocadas pela agricultura subtropical no manejo das tensões interespécies deu origem ao procedimento ecológico.

Palavras-chave: Multiplicação, Filiação, Multiespécie, Domesticação. 